\title{
Research on Enterprise Selection and Risk Prevention of Diversification Strategy
}

\author{
Luqi Wang
}

School of Business Administration, China University of Petroleum-Beijing, Beijing, 102200, China

Keywords: Diversification Strategy, Multiple strategies, Risk prevention

\begin{abstract}
Diversification is an important way for enterprises to expand the scale and realize the growth. In order to spread the enterprise risk, reduce the transaction cost, improve the economic efficiency and expand the emerging market, more and more enterprises have embarked on the road of diversification. However, in the process of the rapid expansion, enterprises may face more uncertainties and great risks. This paper analyzes the management risk, debt risk and exit risk faced by enterprises in the implementation of diversification strategy, and gives corresponding countermeasures and suggestions for the relevant researchers as a reference.
\end{abstract}

\section{Introduction}

In order to expand the scale of investment and find new investment projects, the enterprises inevitably take the path of diversified investment [1]. Because of the uncertainty of the future income and the impossibility to accurately judge the future operation situation, there is a greater risk in diversification than specialization [2]. These risks mainly come from the blindness of investment in the process of expansion, low efficiency of capital use, low investment quality and rapid expansion. Diversification strategy is a strategic form for enterprises to expand their product category and market scope, and to engage in production and business activities in several different business areas, and to meet consumers' individual needs in more market segments. Diversification strategy is an enterprise development strategy relative to specialized management strategy. It is a company's production and operation activities outside the scope of the original leading industry. Diversification strategy has unique advantages in decentralization of business risk and full utilization of enterprises' excess resources. In modern society, the diversified development strategy of enterprises has become an important way for enterprises to grow and expand. How to take the first opportunity in the enterprise diversification determines the fate and future of the enterprise to a great extent. The diversification of products, is refers to the enterprise new products across a variety of industries are not necessarily related, and the production for the series of products; market diversification, is refers to the enterprise products in many markets, including domestic and international regional market, and even the global market; diversified investment areas, is refers to the enterprise the investment is not only concentrated in one area, but also scattered in a number of regional and even all over the world; the diversification of capital, refers to the source of capital and a variety of forms, including physical capital and intangible assets such as stocks, securities, intellectual property, trademark and corporate reputation.

\section{Reasons for Enterprise Selection of Diversification Strategy}

\subsection{Spread Enterprise Risk}

Enterprises carry out diversified operation and invest assets in several different industries [3]. Through this investment, risk can be dispersed effectively. Although this approach may not be able to improve the enterprise's overall profit margins, but can be realized, to the portfolio effect, dispersion of industry risk, reduce corporate profits volatility. Enterprises in the process of production and operation of the risk is very much, and very complex. In this market full of risk, how to effectively avoid or reduce the risk has become an important way for the survival and development of enterprises. 
With the rapid development of science and technology in modern society, the speed of product research and development has been greatly accelerated, and the life cycle of the product has been greatly shortened. If enterprises invest all their capital in the same industry, then the risks faced by enterprises can be imagined as the overall decline of the industry. At this time, it is very important to make a reasonable dispersion of the risk. The implementation of diversification strategy, the implementation of different business combination, the production of different product life cycle, can make the enterprise at any time in the growth stage of the products to avoid the risk of shrinking a product or an industry entered a recession brings to the market, and by different departments, inter industry profits to balance income the function of ensuring the survival and development of enterprises safety and stability. Through diversified operations, enterprises diversify their risks into various business areas.

\subsection{Reduce Transaction Cost}

Through the diversification, the enterprise can make part of the transactions internalize, which can reduce the cost of enterprise [4]. The market transactions can prevent opportunism, reduce information asymmetry and reduce the complexity of the contract signed in trouble, so as to overcome market trading difficulties, saving transaction costs. Enterprise diversification strategy can reduce costs for enterprises from multiple levels, which means that enterprises can get more profits and provide more material guarantee for the survival and development of enterprises. Diversification can effectively reduce transaction costs and improve transaction efficiency. The diversification strategy can save the cost for the enterprise in many ways. In the implementation of enterprise diversification strategy, enterprise into new business units and the original business often has a certain correlation in terms of technology, so in the new business unit can make full use of advantages of the original enterprise, reduce new business pre technology research and development costs, production technology and economy. In the process of diversification, enterprises can promote the new business to some extent by utilizing channel resources, brand image and promotion mode of existing businesses, so as to reduce marketing costs. This initial investment reduces the market development cost of creating new brands and setting up a new image.

\subsection{Improve Economic Benefit}

With the improvement of the quality of life, people's quality of life is also higher and higher, and their consumption capacity is also increasing. Consumer demand presents a multi-directional, multi angle and diversified characteristics. People's consumption is influenced by many factors, there will be a variety of hobbies, the demand for commodities is also showing a different demand shows the characteristic of diversification, the enterprise will according to the market demand, adopt diversification strategy, through diversification to obtain high profits. The relatively mature, the market is basically saturated in the industry, if the enterprises want to get higher growth and profitability, many companies will first think of the diversification strategy, generally rely on lower costs and increase sales, highly concentrated, in the fierce competition in the industry is a big risk, only by new industries or open up a new field higher growth and profitability, is the best means. From the perspective of diversification affecting the market competitiveness, diversified enterprises can reflect their own advantages in the market more than single business enterprises. Moreover, a diversified enterprise can buy and sell a company at the same time, because of its involvement in multiple factors, which greatly increases the competitive power of the market.

\subsection{Expand Emerging Market}

Due to the attraction of higher profits in the external market or larger market opportunities in the future, enterprises will diversify into other business units in order to get more development space and profit source. The view of the attraction of the external market profit can provide theoretical support to the non - related diversification of the enterprise. The ultimate goal of enterprise production and operation is to pursue profit maximization. If the same capital can get more excess profits in other industries, it will attract more enterprises to enter. This also conforms to the flow law of capital, and 
the characteristics of capital tendency to high profit rate determine the direction of capital flow. In the development of emerging markets, the most important thing is to understand the local market, including local culture, traditional customs, market demand, and so on. The scope economy may also have a further synergistic effect, the synergistic effect is the combination of two things, playing more than their simple combination. The joint production of two or more products in one enterprise produces a range economy when it is more cost saving than the production of them separately. The view of scope economy mainly comes from the utilization of the surplus resources and ability of the enterprise. In order to operate some kind of business, enterprises need to carry out specific investment to form surplus resources. The enterprise can use this surplus resources to achieve the purpose of the lowest cost.

\section{Risk and Its Prevention of Enterprise Selection of Diversification Strategy}

\subsection{Management Risk and Its Prevention}

In the formation of enterprise strategy, it relies mainly on the senior leadership of the enterprise, the enterprise strategic manager, the enterprise advisor, the cooperative consulting company or the middle level manager. The strategic vision, strategic experience, strategic intuition and strategic ability of top leaders decide whether they can find hidden risks in strategic investment and maximize their risk elimination. And the limitation of decision-making ability and leadership quality of enterprise decision-makers inevitably forms the risk of enterprise multiple strategy. Compared with professional strategy, diversification strategy is a development from paying attention to the scale economy of enterprises to the scope economy, and expanding the scope and business of mature enterprises in the stage of product life maturity. This expansion must be based on the cultivation of core competitive ability, and it is the use of enterprise resources and management potential. But in practice, a lot of development to a certain size, a certain stage of the enterprise, diversification of understanding is very one-sided, in the absence of internal and external environment opportunities and threats and advantages of a rational and objective analysis of the new into the field without further comprehensive understanding of the situation, blindly follow the trend, one-sided pursuit of enterprise scale business units, growth, the result not only did not increase the core competitiveness of enterprises, but because the shop stalls too large, scattered resources, management range is too large, resulting in the level and efficiency of management of enterprises under severe sliding. The industry is still in the mature period, but if the industry market has become saturated. Enterprises should carry out diversification in the case of internal conditions, in order to seek the space for sustainable development. Whether there is a market opportunity in the emerging industry is also an important external condition for the diversification of enterprises. In the case of more market opportunities, the diversification of enterprises is more likely to be successful. In the case of less market opportunities, enterprises are required to be more cautious when making decisions on whether to diversify.

\subsection{Debt Risk and Its Prevention}

The implementation of diversification strategy is bound to face the risk of barriers in the new industry. When the enterprise is initially involved, the demonstration and analysis of the project is very important to the field investigation and research. But in practice, often for the purpose of grasping the market and occupy the initiative, the project is not a thorough demonstration case, hasty attack, successful experience blindly copy others, a serious violation of the requirements of the project investment decision-making and management mechanism, to face a huge risk in new investment projects and related fields. Diversification strategy is only a choice in the way of business. It is not the choice that all enterprises can make or have to make in the development. In the different stages of the industry or product cycle, the difficulty of enterprise management is different, and the strategy adopted by the enterprise should be different. Enterprises should strive to enter new industries in the period of investment or growth, and avoid entering the mature or declining industries, 
which is determined by competitiveness, development potential and industry barriers. Therefore, it is very important to predict and judge the new industry and new product accurately, which is the key factor for the success of the new field. If the enterprise blindly enters the industry and product in the late life cycle, it will face a lot of risk. Even if a certain industry has certain scale and development characteristics, it also has market attractiveness. Whether enterprises can enter the industry to diversify business, we need to combine industrial opportunities with the overall objectives of an enterprise. If the industry opportunities are not to encourage enterprises to complete the overall goal, enterprises will occupy scarce capital, increase the financial risk of the enterprise. If the industry the opportunity complies with the company's goal, enterprise must also consider whether it has the necessary intervention such as technology, capital and competitiveness.

\subsection{Withdraw Risk and Its Prevention}

Before the diversification of investment, enterprises often seldom take into account the problem of withdrawal. However, if the enterprise is in a bad investment projects but do not retreat, then it may cause the enterprise to the whole army was wiped out. A well designed exit channel can effectively reduce the risk of diversification. In strategic management, it is bound to face risks. In every stage of the enterprise, it is necessary to control it through effective prevention mechanism, to deal with the risk in time, and to control it in a certain range. But in the process of implementation, risk monitoring is lack of effective system management. It lacks effective monitoring, rectifying and remedy system in the implementation of the strategy, which leads enterprises to quit effectively when facing investment risk. The products or markets of these enterprises are combined in the same enterprise entirely out of chance, without any economies of scale and scope. This strategy can exist, mainly some enterprise managers in a previous period of operation, has achieved some success, resulting in inflated sense of self in the subconscious, the unrealistic idea of your ability, think they have can be successful in various fields. Driven by this psychological state, when there are attractive market opportunities in some areas, they will make decisions in the field of business activities regardless of the actual situation, resulting in the failure of operation. Of course, many enterprises are exploring new business areas to avoid competition, but they are in trouble because they are not familiar with new fields, and have many barriers to entry. Therefore, when considering the implementation of the diversification strategy, the enterprise must be positive and prudent.

\section{Conclusions}

The implementation of diversification strategy is based on the comprehensive consideration of the ability and resources of enterprise and the peripheral environment. In practice, the implementations of diversification strategies often fall into a situation of failure in China. The successful implementation of diversification strategies is often based on an objective and comprehensive understanding of enterprise's own competitive ability. The enterprise should establish a comprehensive control mechanism to prevent the management risk, debt risk and exit risk in the implementation process of diversification strategy.

\section{References}

[1] Wu Guoding, Zhang Huili. Does Diversification Reduce Financial Risk? Evidence from Chinese Listed Firms [J]. Journal of Central University of Finance \& Economics, 2015(8): 94-101. [2] Wu Po-yee melody, Wu Jing, Li Hao. Expansion Strategy Analysis of Real Estate Enterprises Based on Risk Diversification [J]. Journal of Engineering Management, 2015, 29(2): 142-147.

[3] Hu Gang, Cao Xing. Research on impact of dynamic capability on diversification strategy under the perspective of knowledge [J]. Science Research Management, 2014, 35(9): 98-105.

[4] Zhao Feng, Wang Tienan, Zhang Liang. An Empirical Study on the Effect of Diversification Strategy on Firm Performance [J]. China Soft Science, 2012(11): 111-122. 